\title{
Risks Identification and Allocation in the Supply Chain of Modular Integrated Construction (MiC)
}

\author{
Ibrahim Y. Wuni ${ }^{*}$ and Geoffrey Q.P. Shen ${ }^{2}$ \\ ${ }^{1}$ Ph.D. Student, Department of Building and Real Estate, The Hong Kong Polytechnic \\ University, Hong Kong \\ 2 Professor, Department of Building and Real Estate, The Hong Kong Polytechnic University, \\ Hong Kong \\ "Corresponding author's e-mail: ibrahim.wuni@connect.polyu.hk
}

\begin{abstract}
Modular integrated construction $(\mathrm{MiC})$ is an offsite construction technique which can improve construction quality, the certainty of the project cost, provide value for money and reduce construction time, waste generation, and carbon emissions. However, $\mathrm{MiC}$ is associated with a unique business model, engineering, supply chain, and stakeholder composition, resulting in bespoke uncertainties and risks. Prominent among them is the uncertainties and risk events in its linked supply chain segments. However, risks identification and allocation in the MiC supply chain segments is not well-established. This research identified and assessed 28 risk events (REs) across the manufacturing, logistics and on-site assembly segments of the MiC supply chain. A principal component analysis generated 10,6 and 12 REs within the modular manufacturing, logistics, and on-site assembly segments, respectively. A fuzzy synthetic evaluation (FSE) modeling revealed that the on-site assembly REs are the most critical set of risk events with a criticality index of 5.58, followed by the modular manufacturing risk events (5.28) and logistics risk events (5.08). These rankings and criticality assessment have profound implications for the practice and praxis $\mathrm{MiC}$ risks management. It is a source of relevant information to stakeholders and practitioners in understanding the $\mathrm{MiC}$ supply chain risk events and may prioritize the riskiest events to improve the performance of $\mathrm{MiC}$ projects. Again, the assessed REs contributes to the checklists of MiC risk events and may form the basis for future studies on the risk of MiC. Future studies may examine the assessed risk events in different countries using larger samples.
\end{abstract}

\section{KEYWORDS}

Risk events; Modular integrated construction; Supply chain; Schedule delays; Uncertainties

\section{INTRODUCTION}

Modular integrated construction $(\mathrm{MiC})$ refers to a construction system where independent building elements, usually completed with finishes, fixtures, and fittings are produced in an offsite factory and then transported to a construction site for final assembly and installation (Hong Kong Buildings Department, 2018). $\mathrm{MiC}$ is a typical offsite construction (OSC) technique where $80-90 \%$ of a whole building can be completed in a factory environment (Smith, 2016). Like OSC, MiC reduces construction time, solid waste generation and water footprint (Jaillon and Poon, 2008). The approach also improves productivity, continuity of workflow and safety of construction workers (Pan et al., 2008). However, the business model of $\mathrm{MiC}$ is associated with a unique engineering, supply chain, stakeholder composition and management requirements different from those of the conventional construction (CC) approach. As such, $\mathrm{MiC}$ is associated with bespoke risks events and uncertainties. Prominent among them is the risk events associated with the MiC supply chain. For instance, dimensional and geometric intolerances of the modular components are recipes for reworks and poor quality (Shahtaheri et al., 2017). Also, the dominant design information gap between designers and manufacturers could trigger scope changes 
resulting in schedule delays (Li et al., 2017). Moreover, cranes malfunction and weather disruptions may generate significant schedule delays (Li et al., 2018). Given the distinct supply chain profiles between $\mathrm{MiC}$ and the $\mathrm{CC}$, risk management strategies of the latter are not directly applicable to the former ( $\mathrm{Li}$ et al., 2013). Also, the impact of risk events on the performance of MiC projects is more pronounced due to its shorter schedules, difficulty in rectifying errors, inflexibility to design changes during construction, and the higher cost of reworks (Shahtaheri et al., 2017).

As a result, there is a growing body of bespoke research on the risks of MiC. For example, Li et al. (2013) identified and assessed risk factors that affect the cost and schedule performance of MiC. Li et al. (2016, 2017, 2018) examined schedule delays and risks of MiC projects in Hong Kong and Shahtaheri et al. (2017) investigated MiC risk management strategies. Previous risks studies on the MiC supply chain revolve around these mainstream risk aspects. However, risk events identification and allocation in the MiC supply chain is not well-established. Such research is crucial because the segments of the MiC supply chain are complex and fragmented but interdependent (Li et al., 2018, 2017) such that disruptions and disturbances in upstream supply chain segments may compromise the continuity of downstream segments. For example, too early delivery of modular elements to a site requires storage space whereas delays in the delivery of modular elements could halt the entire installation process (Li et al., 2018). Therefore, MiC risk management practice and praxis could be enhanced if there is a broadened understanding of the major risk events in its supply chain. As such, this research identified and allocated risk events across the manufacturing, logistics and the on-site assembly segments of the MiC supply chain, drawing on the opinions of international MiC experts.

\section{RESEARCH METHODS AND DATA SOURCES}

The paper adopted a quantitative methodological framework to identify and allocate risks in the MiC supply chain. Following a comprehensive literature review, a checklist of 40 risk events (REs) associated with the supply chain of MiC was developed. However, following structured interviews with experts, the number was reduced to 28 REs.

\begin{tabular}{|c|c|}
\hline $\begin{array}{l}\text { Determine a basic set of criteria or factors. } \\
\Pi=\left\{f_{1}, f_{2}, f_{3}, \ldots \ldots ., f_{m}\right\} \text {, where, } m \text { is the } \\
\text { number of criteria }\end{array}$ & \multirow{2}{*}{$\begin{array}{l}\text { Compute the fuzzy synthetic evaluation } \\
\text { matrix for each criterion or factor. The } \\
\text { matrix is expressed as } \mathrm{R}=\left(\mathrm{r}_{\mathrm{ij}}\right)_{\mathrm{mxn}} \text {, where } \mathrm{r}_{\mathrm{ij}} \\
\text { is the degree to which each alternative } \\
\text { satisfies the criterion } f_{m}\end{array}$} \\
\hline & \\
\hline \multirow[b]{2}{*}{$\begin{array}{l}\text { Establish a set of grade alternatives. } \\
\mathrm{E}=\left\{\mathrm{e}_{1}, \mathrm{e}_{1}, \mathrm{e}_{1}, \ldots . . \mathrm{e}_{\mathrm{n}}\right\} . \\
\text { The set of grade alternatives are the scale } \\
\text { measurement adopted for the study. As } \\
\text { such, the 7-point Likert scale is the set of } \\
\text { grade alternatives such as that: } e_{1}=\text { very } \\
\text { insignificant and } e_{7}=\text { very significant }\end{array}$} & \\
\hline & $\begin{array}{l}\text { Determine the results for the evaluation by } \\
\text { considering the weighting vector and the } \\
\text { fuzzy evaluation matrix using the } \\
\text { equation: } \mathrm{D}=\mathrm{W}_{\mathrm{i}}{ }^{\circ} \mathrm{R}_{\mathrm{i}} \text {, where, } \mathrm{D} \text { is the final } \\
\text { evaluation matrix and }{ }^{\circ} \text { is a fuzzy }\end{array}$ \\
\hline & 7 \\
\hline $\begin{array}{l}\text { Establish the weightings for each criterion or } \\
\text { factor. The weightings (w) for each criterion } \\
\text { can be computed from the mean scores. } W_{i}= \\
\left\{w_{1}, w_{2}, w_{3}, \ldots, w_{m}\right\} \text { where, }\left(0 \leq w_{l} \leq 1\right)\end{array}$ & $\begin{array}{l}\text { Establish the results by normalising the } \\
\text { final evaluation matrix using the equation: } \\
\mathrm{RE}_{\text {index }}=\sum_{i=1}^{5}(D x E) \text {, where } \mathrm{RE}_{\text {index }} \text { is the } \\
\text { index for each } \mathrm{RE} \text { in MiC projects and } \mathrm{D} \\
\& \mathrm{E} \text { remain as previously defined }\end{array}$ \\
\hline
\end{tabular}

Figure 1. Flowchart of the FSE modeling procedure 
A constructive questionnaire scoring system was developed to collect data on the varying criticality of the risk events. The questionnaire was an online survey using survey monkey, LinkedIn messaging and emails. It was distributed to 200 researchers in 15 countries. The experts were requested to indicate the level of criticality of a risk event within the MiC supply chain on a 7-point Likert scale where 1=very insignificant, 2=moderately insignificant, 3=slightly insignificant, 4=neutral, 5=slightly significant, $6=$ moderately significant, $7=$ very significant. Following several reminders, 37 valid responses were received from Malaysia (7), Australia (5), China (10), UK (5), U.S. (4), Singapore (1), and Hong Kong (5). Although it constituted a small response rate of $18.5 \%$, previous international surveys even recorded lower response rates such as 14\% (Osei-Kyei et al., 2017). A principal component analysis was conducted to cluster the risk events and a fuzzy synthetic evaluation (FSE) analysis facilitated modeling of the risk events. Prior to the factor analysis and FSE modeling, the sample size and data were examined against their suitability for factor analysis. The data were analyzed using IBM SPSS Statistics v.25. Figure 1 shows the FSE modeling procedure, adapted from Ameyaw and Chan (2015). FSE is a component of fuzzy set theory (Zadeh, 1965), which uses membership functions to evaluate linguistic variables such as very low, low, moderate etc. These subjective expressions are inherent in the responses of experts regarding the criticality of the risk events. Thus, the paper adopted the FSE because it can conduct an objective assessment of these subjective opinions of the experts (Sadiq and Rodriguez, 2004).

\section{RESULTS AND DATA ANALYSIS}

Preliminary analyses were conducted to ascertain the suitability of the data and sample size for the factor analysis and FSE modeling. Table 1 shows the mean scores and factor weightings of the risk events (REs). Albeit the 1:1 factor to sample size ratio fell short of the 1:5 prerequisite (Lingard and Rowlinson, 2006), other statistical assessments proved the data sufficient for factor analysis and FSE modeling. A Cronbach's Alpha of 0.824 highlighted the high internal consistency and reliability of the scale of the survey instrument. The high Alpha value was expected because the respondents were all experts and understood the Likert scale scoring system. A correlation matrix of the 28 risk events (REs) showed a good association coefficient of at least 0.4 among all events, which is above the threshold of 0.3 (Lingard and Rowlinson, 2006). The anti-image correlation matrix suggested the removal of RE1-0.480, which was lower than the threshold of 0.5 (ibid) but the event was included because of its higher coefficient in the correlation matrix. As a measure of sampling adequacy, the Kaiser-Meyer-Olkin (KMO) Test of the 28 variables resulted in a high value of 0.725 , which is within an acceptable range and as such, the data is suitable for factor analysis. The Bartlett Test of Sphericity showed a $\chi^{2}$ value of 148.560 at a significant $p$ value of 0.000 , indicating that the correlation matrix of the sample was not an identity matrix and hence, the null hypothesis should be rejected.

Following these statistical assessments, the factor analysis (principal component analysis) was conducted. The Varimax rotation with Kaiser Normalization converged in 8 iterations at three-factor groupings. A parallel analysis using the Eigenvalue Monte Carlo Simulation syntax of SPSS (O'Connor, 2000), reaffirmed the three-factor groupings. Table 2 shows the factor extractions and their loadings. The weightings of the risk events (REs) were computed based on the formula suggested in Yeung et al. (2007) $W_{i}=\frac{M_{i}}{\sum M_{\ddot{\mu}}}$

Where $W_{i}$ denotes the weighting of each RE or REG; $M_{i}$ denotes the mean score value of each RE or REG; and $\sum M_{\ddot{\mu}}$ denotes the sum of mean scores of all REs or REGs.

It was then useful to ascertain the most critical risk event groupings (REGs) based on their membership functions. The membership functions of the REGs are determined from the membership functions of each $\mathrm{RE}$ using the percentage responses for the grades in the Likert scale for each risk event. For instance, the summary statistics showed that $21.1 \%$ of experts graded "design information gap between designer and manufacturer (RE9)" as moderately significant, $50.8 \%$ as significant and $28.1 \%$ as very significant. As such, its membership function (MF) is computed as: 
$\mathrm{MF}_{(\mathrm{RE} 9)}=\frac{0.000}{V I(1)}+\frac{0.000}{I(2)}+\frac{0.000}{M I(3)}+\frac{0.000}{N(4)}+\frac{0.211}{S(5)}+\frac{0.508}{M S(6)}+\frac{0.281}{V S(7)}$

This can also be expressed as $\mathrm{MF}_{(\mathrm{RE} 9)}=(0.00,0.00,0.00,0.00,0.21,0.51,0.28)$.

Table 1. Mean scores and factor weightings of the MiC supply chain risk events

\begin{tabular}{|c|c|c|c|c|c|}
\hline No. & Risk Events & $\begin{array}{l}\text { Mean } \\
\text { Score } \\
\text { of REs }\end{array}$ & $\begin{array}{l}\text { Weightings } \\
\text { for each RE }\end{array}$ & $\begin{array}{l}\text { Total MS } \\
\text { for each } \\
\text { REG }\end{array}$ & $\begin{array}{l}\text { Weightings } \\
\text { for each } \\
\text { REG }\end{array}$ \\
\hline RE1 & Changes in the operation rate of modular factory & 6.19 & 0.108 & & \\
\hline RE2 & $\begin{array}{l}\text { Vertical \& horizontal errors in fabricating } \\
\text { modular elements }\end{array}$ & 6.16 & 0.108 & & \\
\hline RE3 & Lack of lifting equipment at manufacturing plant & 5.74 & 0.100 & & \\
\hline RE4 & Delays in modular materials procurement & 5.26 & 0.092 & & \\
\hline RE5 & $\begin{array}{l}\text { Mechanical malfunction of modular production } \\
\text { equipment }\end{array}$ & 5.11 & 0.089 & & \\
\hline RE6 & Misplacement of modules on storage site & 5.86 & 0.102 & & \\
\hline RE7 & Poorly produced modules & 6.18 & 0.108 & & \\
\hline RE8 & $\begin{array}{l}\text { Geometric conflicts between components during } \\
\text { manufacturing }\end{array}$ & 6.09 & 0.106 & & \\
\hline RE9 & $\begin{array}{l}\text { Design information gap between designer and } \\
\text { manufacturer }\end{array}$ & 6.07 & 0.106 & & \\
\hline RE10 & Shortage of modular Production materials & 4.58 & 0.080 & & \\
\hline REG1 & Modular manufacturing risk events & & & $\mathbf{5 7 . 2 4}$ & 0.372 \\
\hline RE11 & $\begin{array}{l}\text { Distance between the site and the module } \\
\text { production factory }\end{array}$ & 6.04 & 0.186 & & \\
\hline RE12 & Extreme weather disruptions & 5.33 & 0.164 & & \\
\hline RE13 & Excessive approval procedures & 5.65 & 0.174 & & \\
\hline RE14 & Logistic information inaccuracy & 4.47 & 0.138 & & \\
\hline RE15 & $\begin{array}{l}\text { Traffic, Congestion, transportation vehicle and } \\
\text { road damage }\end{array}$ & 4.39 & 0.135 & & \\
\hline RE16 & Delay in the delivery of modules & 6.54 & 0.202 & & \\
\hline REG2 & Logistics risk events & & & 32.42 & 0.211 \\
\hline RE17 & Production schedules not reflecting site conditions & 3.91 & 0.061 & & \\
\hline RE18 & $\begin{array}{l}\text { Improper lifting equipment selection on the } \\
\text { construction site }\end{array}$ & 6.07 & 0.095 & & \\
\hline RE19 & Errors in modular connection on the site & 6.33 & 0.099 & & \\
\hline RE20 & $\begin{array}{l}\text { Rework due to discrepancy or interruptions } \\
\text { between drawings }\end{array}$ & 6.37 & 0.099 & & \\
\hline RE21 & Dimensional and geometric variability & 5.81 & 0.091 & & \\
\hline RE22 & Change of project design or scope & 5.77 & 0.090 & & \\
\hline RE23 & Modular elements installation error & 5.61 & 0.087 & & \\
\hline RE24 & Tower crane breakdown or malfunction & 5.60 & 0.087 & & \\
\hline RE25 & Slow quality inspection process & 5.61 & 0.087 & & \\
\hline RE26 & Obscurity in identifying proper modular elements & 5.09 & 0.079 & & \\
\hline RE27 & Inadequate planning and scheduling & 5.37 & 0.084 & & \\
\hline RE28 & Inefficient verification of modules & 2.63 & 0.041 & & \\
\hline REG3 & $\begin{array}{l}\text { On-site assembly risk events } \\
\text { Total Risk Events Grouping (REG) }\end{array}$ & & & $\begin{array}{l}64.17 \\
153.83\end{array}$ & 0.417 \\
\hline
\end{tabular}

Following the same approach, the membership function for each RE was computed as shown in column four of Table 3. To compute the MFs of the REGs, the formula in step 5 of Figure 1 was used. $\mathrm{D}_{\mathrm{i}}=W_{i}{ }^{\circ} R_{i}$ 
Where $\mathrm{D}$ denotes the final evaluation matrix, $W_{i}$ is the weightings for all REs under each REG and $R_{i}$ denotes the membership function matrix for each REG.

Table 2. Risk events factor extractions and their loadings

\begin{tabular}{|c|c|c|c|c|c|}
\hline No. & Risk Events & $\begin{array}{l}\text { Factor } \\
\text { Loadings }\end{array}$ & Eigenvalue & $\begin{array}{l}\% \text { of } \\
\text { variance } \\
\text { explained }\end{array}$ & $\begin{array}{l}\text { Cumulative } \\
\% \text { of variance } \\
\text { explained }\end{array}$ \\
\hline & Modular manufacturing risk events & & 11.146 & 39.807 & 39.807 \\
\hline RE4 & Delays in modular materials procurement & 0.860 & & & \\
\hline RE5 & $\begin{array}{l}\text { Mechanical malfunction of modular } \\
\text { production equipment }\end{array}$ & 0.848 & & & \\
\hline RE10 & Shortage of modular Production materials & 0.815 & & & \\
\hline RE9 & $\begin{array}{l}\text { Design information gap between designer } \\
\text { and manufacturer }\end{array}$ & 0.771 & & & \\
\hline RE7 & Poorly produced modules & 0.728 & & & \\
\hline RE8 & $\begin{array}{l}\text { Geometric conflicts between components } \\
\text { during manufacturing }\end{array}$ & 0.682 & & & \\
\hline RE6 & Misplacement of modules on storage site & 0.611 & & & \\
\hline RE2 & $\begin{array}{l}\text { Vertical \& horizontal errors in fabricating } \\
\text { modular elements }\end{array}$ & 0.597 & & & \\
\hline RE3 & $\begin{array}{l}\text { Lack of lifting equipment at the } \\
\text { manufacturing plant }\end{array}$ & 0.524 & & & \\
\hline RE1 & $\begin{array}{l}\text { Changes in the operation rate of modular } \\
\text { factory }\end{array}$ & 0.480 & & & \\
\hline & Logistics risk events & & 3.151 & 11.255 & 51.062 \\
\hline RE16 & Delay in the delivery of modules & 0.844 & & & \\
\hline RE15 & $\begin{array}{l}\text { Traffic, Congestion, transportation vehicle } \\
\text { and road damage }\end{array}$ & 0.825 & & & \\
\hline RE14 & Logistic information inaccuracy & 0.766 & & & \\
\hline RE11 & $\begin{array}{l}\text { Distance between the site and the module } \\
\text { production factory }\end{array}$ & 0.653 & & & \\
\hline RE13 & Excessive approval procedures & 0.646 & & & \\
\hline RE12 & Extreme weather disruptions & 0.587 & & & \\
\hline & On-site assembly risk events & & 2.413 & 8.617 & 59.679 \\
\hline RE27 & Inadequate planning and scheduling & 0.899 & & & \\
\hline RE28 & Inefficient verification of modules & 0.889 & & & \\
\hline RE17 & $\begin{array}{l}\text { Production schedules not reflecting site } \\
\text { conditions }\end{array}$ & 0.829 & & & \\
\hline RE24 & Tower crane breakdown or malfunction & 0.829 & & & \\
\hline RE26 & $\begin{array}{l}\text { Obscurity in identifying proper modular } \\
\text { elements }\end{array}$ & 0.800 & & & \\
\hline RE25 & Slow quality inspection process & 0.796 & & & \\
\hline RE22 & Change of project design or scope & 0.752 & & & \\
\hline RE21 & Dimensional and geometric variability & 0.718 & & & \\
\hline RE23 & Modular elements installation error & 0.664 & & & \\
\hline RE20 & $\begin{array}{l}\text { Rework due to discrepancy or interruptions } \\
\text { between drawings }\end{array}$ & 0.612 & & & \\
\hline RE18 & $\begin{array}{l}\text { Improper lifting equipment selection on the } \\
\text { construction site }\end{array}$ & 0.521 & & & \\
\hline RE19 & Errors in modular connection on the site & 0.521 & & & \\
\hline
\end{tabular}

Note-Extraction method: Principal Component Analysis. Rotation method: Varimax with Kaiser Normalization. Rotation converged in 8 iterations. 


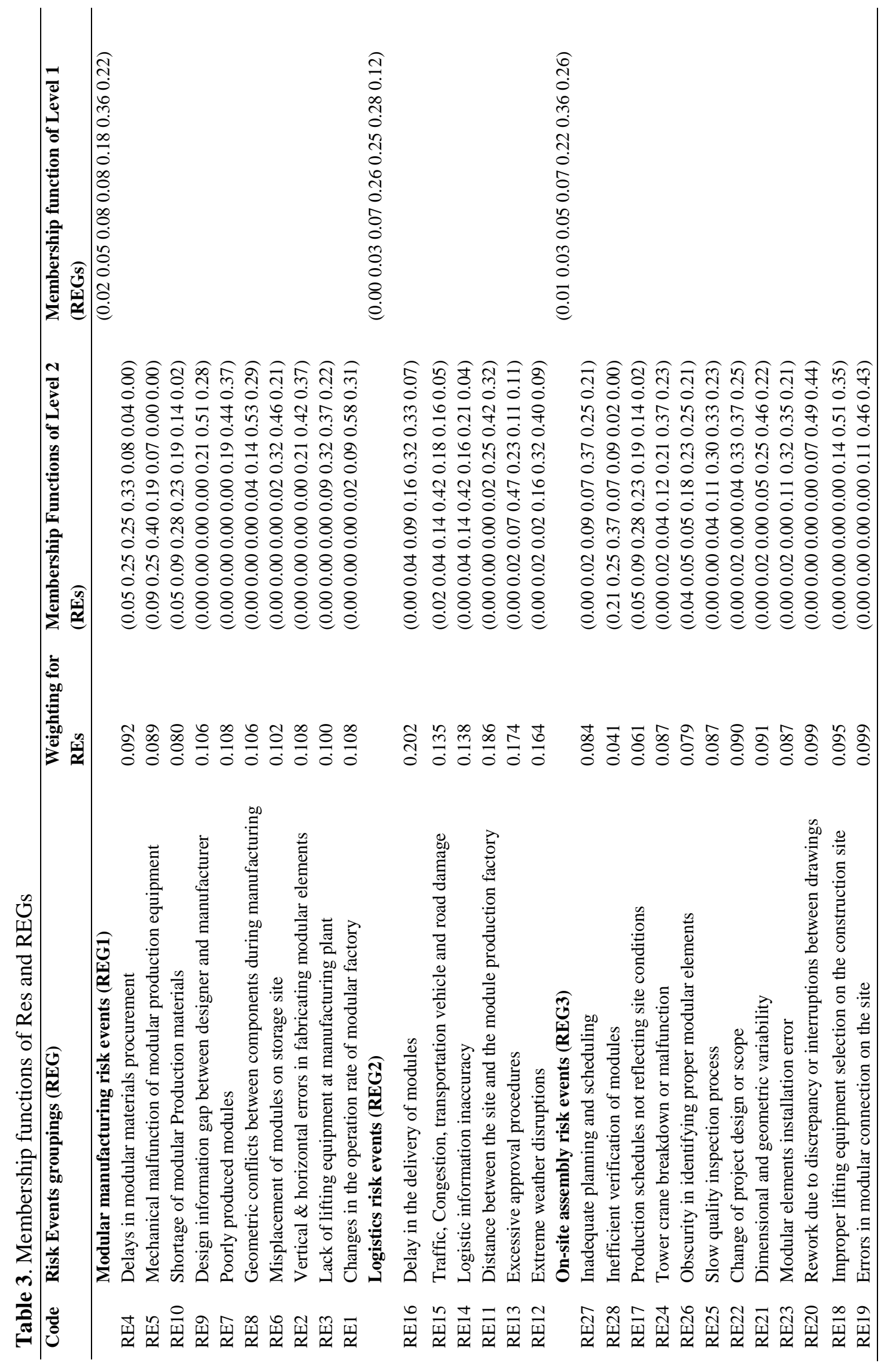


For instance, considering REG2- Logistics risk events (Table 1), the weightings for all the REs under this principal component (i.e. RE11, RE12, RE13, RE14, RE15, and RE16) can be expressed as:

$W_{2}=(0.186,0.164,0.174,0.138,0.135,0.202)$ and $R=\left[\begin{array}{lllllll}0.00 & 0.00 & 0.00 & 0.02 & 0.25 & 0.42 & 0.32 \\ 0.00 & 0.02 & 0.02 & 0.16 & 0.32 & 0.40 & 0.09 \\ 0.00 & 0.02 & 0.07 & 0.47 & 0.23 & 0.11 & 0.11 \\ 0.00 & 0.04 & 0.14 & 0.42 & 0.16 & 0.21 & 0.04 \\ 0.02 & 0.04 & 0.14 & 0.42 & 0.18 & 0.16 & 0.05 \\ 0.00 & 0.04 & 0.09 & 0.16 & 0.32 & 0.33 & 0.07\end{array}\right]$

Therefore, the membership function for REG2 is computed as:

$\mathrm{D}_{2}=(0.186,0.164,0.174,0.138,0.135,0.202) \times\left[\begin{array}{lllllll}0.00 & 0.00 & 0.00 & 0.02 & 0.25 & 0.42 & 0.32 \\ 0.00 & 0.02 & 0.02 & 0.16 & 0.32 & 0.40 & 0.09 \\ 0.00 & 0.02 & 0.07 & 0.47 & 0.23 & 0.11 & 0.11 \\ 0.00 & 0.04 & 0.14 & 0.42 & 0.16 & 0.21 & 0.04 \\ 0.02 & 0.04 & 0.14 & 0.42 & 0.18 & 0.16 & 0.05 \\ 0.00 & 0.04 & 0.09 & 0.16 & 0.32 & 0.33 & 0.07\end{array}\right]$

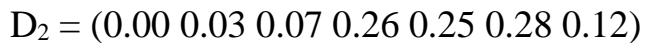

Using the same approach, the membership functions of the remaining REGs are computed and shown in column 5 of table 3. Given the membership functions for each REG, the criticality index (table 4) for each principal component was computed using the following equation:

$\mathrm{REG}_{\text {index }}=\sum_{i=1}^{5}(D * E)$

Where, $\mathrm{REG}_{\text {index }}$ is the index for each REG in the MiC supply chain, $\mathrm{D} \& \mathrm{E}$ remain as previously defined. The indices for all risk events groupings, their criticality level and ranking are shown in Table 4 . The index for each REG is computed as follows:

REG1 $=(0.02,0.05,0.08,0.08,0.18,0.36,0.22) \times(1,2,3,4,5,6,7)=\mathbf{5 . 2 8}$

REG2 $=(0.00,0.03,0.07,0.26,0.25,0.28,0.12) \times(1,2,3,4,5,6,7)=\mathbf{5 . 0 8}$

REG3 $=(0.01,0.03,0.05,0.07,0.22,0.36,0.26) \times(1,2,3,4,5,6,7)=\mathbf{5 . 5 8}$

Table 4. Criticality Indices of the REGs in the MiC Supply Chain

\begin{tabular}{lllll}
\hline No. & Factor groupings & Index & Criticality & Ranking \\
\hline REG1 & Modular manufacturing risk events & 5.28 & Very Critical & 2 \\
REG2 & Logistics risk events & 5.08 & Critical & 3 \\
REG3 & On-site assembly risk events & 5.58 & Very Critical & 1 \\
\hline
\end{tabular}

DISCUSSIONS OF THE RISK EVENTS GROUPINGS (REGs)

The fuzzy synthetic evaluation (FSE) generated 3 critical risk events groupings in the supply chain of MiC. From table 4, the on-site assembly risk events ranked first with a criticality index of 5.58, tailed by modular manufacturing risk events and then, logistics risk events with criticality indices of 5.28 and 5.08, respectively. These rankings offer relevant information to MiC practitioners and project managers on riskiest events within the MiC supply chain. This could assist them in prioritizing the group (s) of risk events which are deemed the most critical in the MiC supply chain.

\section{On-site Assembly Risk Events}

This risk events grouping explains $8.62 \%$ of the total variance of the factor analysis and was ranked first with a criticality index of 5.58. It was considered very critical on the 7-point Likert scale. This principal component has 12 sub-risk events. Of these, inadequate planning and scheduling (RE27) had the highest factor loading of 0.899 and scored a mean of 5.37. Inefficient verification of modules (RE28) had the second highest factor loading of 0.889. Production schedules not reflecting site conditions (RE17) and tower crane breakdown or malfunction (RE24) both had the third highest factor loading of 0.829 but scored means of 2.63 and 5.60, respectively. These risk events result in excessive schedule delays, 
reworks, quality problems and poor stability (Shahtaheri et al., 2017). The remaining risk events within this group are recipes for loss of assembly time and time overrun (Li et al., 2016, 2017, 2018).

\section{Modular Manufacturing Risk Events}

This risk events grouping accounts for $39.81 \%$ of the total variance of the factor analysis and was ranked second with a criticality index of 5.28. It was considered very critical on the 7-point Likert scale. This principal component has 10 sub-risk events. Of these, delays in modular materials procurement (RE4), mechanical malfunction of modular production equipment (RE5), shortage of modular production materials (RE10), design information gap between designer and manufacturer (RE9) and poorly produced modules (RE7) had the top 5 highest factor loadings of $0.860,0.848,0.815,0.771$, and 0.728 , respectively. The success and suitability of the modular elements largely depend on the quality of modular design and specification. However, it is still a common practice for the design team to produce drawings 'behind the wall' and expect the manufacturer to interpret the specifications 'over the wall'. This unhealthy practice has triggered quality concerns as it generates problems of discrepancies for manufacturers (Li et al., 2017). Again, modular fabrication depends on the availability of the requisite paraphernalia and materials such as modular production equipment, materials etc. Thus, delays in procuring some of these materials could compromise the production of modules, resulting in schedule delays ( $\mathrm{Li}$ et al., 2018). The impact could be multiplied if 'Just-in-Time' delivery arrangement is made (Kong et al., 2018). Also, in conditions where there are no safety modular production equipment, mechanical breakdown or malfunction of equipment could result in lower production output. Such malfunction would result in the inability to produce the scheduled number of modules for the given time frame, leading to possible schedule delays ( $\mathrm{Li}$ et al., 2018). The remaining risk events within this grouping had factor loadings less than 0.7 and may not be equally important.

\section{Logistics Risk Events}

This risk events grouping explains $11.26 \%$ of the total variance of the factor analysis and was ranked third with a criticality index of 5.08. It was considered critical on the 7-point Likert scale. This component has 6 sub-risk events. Of these, delay in the delivery of modules (RE16) had the highest factor loading of 0.844 followed by 'traffic, congestion, transportation, vehicle, and road damage' (RE15) and Logistic information inaccuracy (RE14) having factor loadings of 0.825 and 0.766 , respectively. The last three include distance between the site and the module production factory (0.653), excessive approval procedures (0.646) and extreme weather disruptions (0.587). For reasons such as extreme weather disruptions, unavailability of truck drivers, traffic congestion as well as transport vehicular and road damages, the delivery of modules could be delayed significantly. Such delays have triggered significant additional cost in the six-day cycle assembly of prefabricated public housing projects in Hong Kong (Li et al., 2018). Excessive approval procedures could lead to schedule delays and the logistics information inaccuracy may result in the delivery of inappropriate modules or to the wrong place ( $\mathrm{Li}$ et al., 2018; $\mathrm{Li}$ et al., 2013).

\section{CONCLUSION}

The study investigated the risk events in the MiC supply chain. It identified and assessed the criticality of 28 risk events across the manufacturing, logistics and on-site assembly segments of the MiC supply chain. A principal component analysis generated 10,6 and 12 risk events within the manufacturing, logistics and on-site assembly segments, respectively. An FSE modeling revealed that the on-site assembly risk events are the most critical set of risks events with a criticality index of 5.58, followed by the modular manufacturing risk events (5.28) and logistics risk events (5.08). These rankings and criticality assessment have profound implications for MiC practice. Practitioners may prioritize the riskiest events to improve the performance of MiC. Again, the paper contributes to the extant literature on the risk of MiC and may form the basis for future studies on the risk of MiC. However, a generalization of the results is constrained owing to the smaller sample size which may not reflect the global perspective. Notwithstanding, the results are reliable based on statistical assessments. 


\section{ACKNOWLEDGMENTS}

The paper constitutes a part of a Ph.D. research project at The Hong Kong Polytechnic University and fully funded under the Hong Kong Ph.D. Fellowship Scheme (HKPFS) by the Research Grants Council of the Hong Kong Special Administrative Region. However, any opinions, findings, conclusions or recommendations expressed in the paper are those of the authors and do not necessarily reflect the views of the Research Grants Council

\section{REFERENCES}

Ameyaw, E.E., Chan, A.P.C., 2015. Evaluation and ranking of risk factors in public-private partnership water supply projects in developing countries using a fuzzy synthetic evaluation approach. Expert Syst. Appl. 42, 5102-5116. https://doi.org/10.1016/j.eswa.2015.02.041

Hong Kong Buildings Department, 2018. Modular Integrated Construction. Hong Kong.

Jaillon, L., Poon, C.S., 2008. Sustainable construction aspects of using prefabrication in a dense urban environment: A Hong Kong case study. Constr. Manag. Econ. 26, 953-966. https://doi.org/10.1080/01446190802259043

Kong, L., Li, H., Luo, H., Ding, L., Zhang, X., 2018. Sustainable performance of just-in-time (JIT) management in time-dependent batch delivery scheduling of precast construction. J. Clean. Prod. 193, 684-701. https://doi.org/10.1016/j.jclepro.2018.05.037

Li, C.Z., Hong, J., Fan, C., Xu, X., Shen, G.Q., 2018. Schedule delay analysis of prefabricated housing production: A hybrid dynamic approach. J. Clean. Prod. 195, 1533-1545. https://doi.org/10.1016/j.jclepro.2017.09.066

Li, C.Z., Hong, J., Xue, F., Shen, G.Q., Xu, X., Mok, M.K., 2016. Schedule risks in prefabrication housing production in Hong Kong: a social network analysis. J. Clean. Prod. 134, 482-494. https://doi.org/10.1016/j.jclepro.2016.02.123

Li, C.Z., Shen, G.Q., Xue, F., Luo, L., Xu, X., Sommer, L., 2017. Schedule risk modeling in prefabrication housing production. J. Clean. Prod. 153, 692-706. https://doi.org/10.1016/j.jclepro.2016.11.028

Li, H.X., Al-Hussein, M., Lei, Z., Ajweh, Z., 2013. Risk identification and assessment of modular construction utilizing a fuzzy analytic hierarchy process (AHP) and simulation. Can. J. Civ. Eng. 40, 1184-1195. https://doi.org/10.1139/cjce-2013-0013

Lingard, H., Rowlinson, S., 2006. Letter to the Editor. Constr. Manag. Econ. 24, 1107-1109. https://doi.org/10.1080/01446190601001620

O'Connor, B.P., 2000. SPSS and SAS programs for determining the number of components using parallel analysis and Velicer's MAP test. Behav. Res. Methods, Instruments, Comput. 32, 396-402. https://doi.org/10.3758/BF03200807

Osei-Kyei, R., Chan, A.P.C., Ameyaw, E.E., 2017. A fuzzy synthetic evaluation analysis of operational management critical success factors for public-private partnership infrastructure projects. Benchmarking An Int. J. 24, 2092-2112. https://doi.org/10.1108/BIJ-07-2016-0111

Pan, W., Gibb, A.G.F., Dainty, A.R.J., 2008. Leading UK housebuilders' utilization of offsite construction methods. Build. Res. Inf. 36, 56-67. https://doi.org/10.1080/09613210701204013

Sadiq, R., Rodriguez, M.J., 2004. Fuzzy synthetic evaluation of disinfection by-products - A risk-based indexing system. J. Environ. Manage. 73, 1-13. https://doi.org/10.1016/j.jenvman.2004.04.014

Shahtaheri, Y., Rausch, C., West, J., Haas, C., Nahangi, M., 2017. Managing risk in modular construction using dimensional and geometric tolerance strategies. Autom. Constr. 83, 303-315. https://doi.org/10.1016/j.autcon.2017.03.011

Smith, R.E., 2016. Off-Site and Modular Construction Explained [WWW Document]. Natl. Inst. Build. Sci. URL https://www.wbdg.org/resources/site-and-modular-construction-explained (accessed 11.11.18).

Yeung, J.F.Y., Chan, A.P.C., Chan, D.W.M., Li, L.K., 2007. Development of a partnering performance index (PPI) for construction projects in Hong Kong: A Delphi study. Constr. Manag. Econ. 25, 1219-1237. https://doi.org/10.1080/01446190701598673

Zadeh, A., 1965. Fuzzy Sets. Inf. Control 8, 338-353. https://doi.org/10.1016/S0019-9958(65)90241-X 